\title{
GOVERNANÇA DEMOCRÁTICA EM REDE: O POSICIONAMENTO DAS ONGs DE VIÇOSA - MG
}

\author{
P. M. M. OLIVEIRA*, P. T. OLIVEIRA, B. TAVARES \\ Universidade Federal de Viçosa \\ pamelamartinsufv@gmail.com*
}

Submetido 15/07/2016 - Aceito 16/01/2018

DOI: $10.15628 /$ holos.2018.4838

\section{RESUMO}

O artigo pretende avaliar a interação existente entre ONGs na cidade de Viçosa - Minas Gerais e outras instituições como órgãos públicos, consórcios, terceiro setor e empresa privadas a partir de uma perspectiva de análise de rede e de governança democrática, observando suas conexões e construções sociais de grupo. Uma vez identificada o desenho da estrutura dessa rede por meio do uso do software Pajek $^{\circledR}$, foi realizada a análise do seu comportamento a fim de compreender as relações empíricas e técnicas instauradas nestas entidades. O desenho da rede foi avaliado por meio das análises de características que revelam a densidade, núcleos e centralidade das relações estabelecidas. $O$ estudo apontou que muito do potencial dessas ONGs nos processos de trocas de informação e aprendizagem coletiva poderiam estar sendo melhor utilizado.

PALAVRAS-CHAVE: Redes, Governança Democrática, ONGs.

\section{DEMOCRATIC GOVERNANCE NETWORK: POSITIONING OF NGOS IN VIÇOSA - MG}

The article aims to evaluate the interaction between NGOs and other institutions such as government agencies, consortiums, third sector and private business from a network analysis perspective and democratic governance. Once identified the design of the structure of this network through the use of Pajek ${ }^{\circledR}$ software was conducted the analysis of their behavior in order to understand the empirical and technical relations brought these entities. The design of the network was evaluated through the analysis of characteristics that reveal the density, core and centrality of relationships established.

The study found that much of the potential of these NGOs in information exchange processes and collective learning could be being better used.

KEYWORDS: Network, Democratic Governance, NGOs. 


\section{INTRODUÇÃO}

O cenário globalizado contemporâneo tem exigido uma mudança de comportamento das organizações no que se refere à maneira de se conectar à estrutura global, assim, tem-se que novas formas de organização entre atores, públicos e privados, tem crescido. Nesse sentido, as redes têm sido discutido por teóricos contemporâneos a exemplo de Bastos (2011), Carrion (2010), Gohn (2014) que apontam esse tipo de organização como uma maneiras de atuar de forma conjunta sem que contudo, necessite abrir mão da autonomia das instituições que a compõe. Estas novas formações ocorrem tanto no âmbito público quanto no privado, já que o Estado objetivando atingir sua finalidade de forma mais eficaz e abrangente, torna-se participante dessa dinâmica em rede e muitas vezes ocupa posição de grande representatividade com papel articulador.

O conceito de Governança Democrática em Rede auxilia no entendimento das relações instauradas entre organizações, este é concebido como a estruturação de atores sociais que por meio de negociações dentro de um arcabouço regulatório contribuem para um propósito público (DENHARDT, 2012). Apresenta-se ainda como uma forma de estruturação em rede onde o objetivo final é o alcance do benefício social democrático.

Desta forma, a análise de rede como técnica, fornece parâmetros necessários à compreensão da estrutura de Governança Democrática, uma vez que fornece um desenho da estrutura e dos elos de conexão existentes entre os diversos atore sociais e fornece um panorama das relações horizontais estabelecidas.

Nesse contexto de análise em rede, pode-se refletir acerca do papel desempenhado pelas Organizações Não Governamentais - ONGs que podem ser entendidas como uma forma particular de organização independente do Estado que se dedicam à tarefa de promoção social sem fins lucrativos, e tem como objetivo final a busca pela melhoria das condições de vida de setores mais oprimidos (Montenegro, 1994).

De acordo com Buarque e Vainsencher (2001) o que diferencia as ONGs das demais organizações sociais que as rodeiam é a concentração de esforços para solucionar problemas externos aos participantes da própria organização. Isto implica que não necessariamente, um gestor de uma ONG deve estar sendo atingido pela problematização do contexto em questão.

Sob a perspectiva de rede, torna-se notável a importância de um bom posicionamento daquelas instituições para obtenção de melhor desempenho institucional, uma vez que "o acesso a recursos e o impacto das ONGs sobre o ambiente em que atuam têm relação direta com o desenho das redes" (Fontes, 2004, p. 284).

Este artigo pretende avaliar a interação existente entre ONGs na cidade de Viçosa - Minas Gerais e outras instituições como órgãos públicos, consórcios, terceiro setor e empresa privadas a partir de uma perspectiva de análise de rede e de governança democrática, observando suas conexões e construções sociais de grupo.

Para o desenvolvimento deste artigo, foi utilizado um catálogo desenvolvido por uma das ONG's envolvidas no estudo o qual reuniu as principais informações das demais instituições e suas relações. Para obtenção de uma percepção do arcabouço que envolve o sistema de informação e as construções sociais dos grupos estudados, utilizou-se a metodologia de análise de redes.

A questão que buscou-se investigar neste estudo pode ser descrita da seguinte forma: Qual a inter-relação existente entre as ONGs de Viçosa - MG e como elas se posicionam dentro de uma Governança Democrática em Rede? Ao identificar as conexões estabelecidas entre as 
ONGs de Viçosa e o seu comportamento em meio a uma estrutura de Governança, pretende-se compreender as relações empíricas e técnicas instauradas entre estas entidades.

Além da presente introdução, este artigo é constituído por outras três seções. No primeiro momento, foram destacados aspectos conceituais a respeito da organização de atores sócias em rede, e em seguida, foi apresentado o contexto das ONGs e da governança democrática tratada neste trabalho. A terceira seção trata dos aspectos metodológicos e a utilização do Software PAJEK $^{\circledR}$ de análise de rede, bem como o detalhamento de categorias abordadas para classificação da rede. A seção subsequente relata os resultados obtidos com esta pesquisa e as considerações dos autores.

\section{REFERENCIAL TEÓRICO}

\subsection{A organização de atores sociais em rede}

O estudo de redes sociais, envolvendo uma análise empírica, torna-se uma atividade complexa à medida que o próprio objeto a ser observado encontra-se em constante movimento. De acordo com Mizruchi (2006) o conteúdo das relações sociais é determinado por sua estrutura. Nesse sentido, a reunião de indivíduos, instituições, grupos ou organizações voltadas para a construção de um objetivo comum, em que os sujeitos são diversos e variáveis torna as ligações e relações cada vez mais complexas.

O objetivo de uma análise de rede social "é demonstrar que a análise de uma díade (interação entre dois atores) só tem sentido em relação ao conjunto das outras díades da rede, porque a sua posição estrutural tem necessariamente um efeito" (Marteletto, 2001, p. 72). Não há necessariamente uma estrutura hierárquica formalizada ou um posicionamento estático garantido pelas relações instauradas. $O$ desenho e redesenho da rede só pode ser entendido ao observar-se o todo, e principalmente ao considerar-se que cada elo instituído representa uma entidade independente e participante de demais interações e estruturas que não podem ser mapeadas por completo.

Ao determinar-se um recorte temporal e local para análise de uma formação de rede, fazse necessário compreender a existência de macro e micro estruturas que envolvem as instituições observadas. As macroestruturas dizem respeito à rede geral levando em consideração o tamanho e a densidade do grupo. Ao se analisar o tamanho de uma rede de informações, considera-se o número de elos no total, envolvidos no desenho. Porém, ainda que uma rede possua um tamanho expressivo, é de suma importância observar a concentração de relações instauradas e como elas se agrupam em torno delas mesmas (densidade). Trata-se da formação de subgrupos que podem indicar um potencial de comunicação e troca de informações que garantem melhor atuação dos indivíduos dentro e fora do desenho (Ribeiro \& BASTOS, 2011, p. 283).

Já as microestruturas que envolvem uma rede social são as ligações instauradas entre os elos de forma independente. A análise da microestrutura possibilita observar atores centrais e periféricos e associá-los a possíveis relações de poder. Por exemplo, atores centrais que possuem maior número e intensidade de relações formadas em torno de um nó, facilitam a distribuição de riscos e uma maior independência com relação à rede como um todo. Isto porque, "o maior 
número de vínculos diversifica as oportunidades de satisfação de suas necessidades e os torna menos dependentes" (Ribeiro \& Bastos, 2011, p. 283).

Apesar da concepção de relações sociais exigir uma profunda análise cultural de padrões e contextos, a análise de rede se baseia numa noção clara da importância das relações sociais grupais ou individual. "Com a ênfase que dá às relações sociais concretas em vez de às categorias, a análise de redes apresenta uma concepção mais dinâmica da ação social do que os modelos normativos ou estruturais tradicionais" (Mizzruchi, 1994, p.81).

A análise da eficiência e eficácia do desenvolvimento da rede vai depender da manutenção da rede e do fluxo de informação gerada e disponibilizada pelos atores envolvidos. Fatores como clareza, expectativas, nível de regulamentação e incrementação de capacidades dentre outros serão de fundamental influência na continuação e na força das relações estabelecidas na rede. (Fachinelli, Marcon \& Moinet, 2001). Ademais, é necessário que se mantenha o posicionamento de rede de atores independentes, dando liberdade às ações específicas de cada instituição. Neste sentido, Pardini et al. (2012) alerta que uma rede de relações sociais pode ser extensa, todavia, se suas relações não forem bem geridas, isto não se torna garantia de sucesso do empreendimento.

Silva et al. (2012) e Souza et al. (2012) identificam que o cerne da definição de rede está na busca pela sinergia por meio de parcerias em uma dinâmica que objetiva resultados comuns, nesse sentido, pode ser definida como um grupo de atores ou nós que possuem relações uns com os outros. Já Ribeiro e Bastos (2011) interpretam que as relações ou vínculos estabelecidos em uma estrutura de rede são caracterizados por fluxos de informação. Fluxos, nós e vínculos constituem os elementos básicos de uma rede, onde nós representam os atores agrupados em torno de um objetivo comum e vínculos são laços existentes entre esses atores.

O ambiente competitivo no qual as organizações estão inseridas do qual também fazem parte as ONG é marcado por fortes pressões que exigem posicionamentos diferenciados quanto a forma de organização a fim de obter melhores ganhos competitivos. Balestrin e Verschoore (2008) defendem que essas pressões sofridas pelas organizações podem ser usadas como estímulo para a busca de cooperação como forma de alcançar vantagens competitivas ou gerar soluções para problemas comuns. As interações obtidas por meio da rede corresponde à capacidade dos participantes estabelecerem conexões entre si e podem ser avaliadas por meio de diferentes perspectivas como conectividade, densidade, existência de cliques, equivalência estrutural, centralidade, proximidade, dentre outras (Balestrin \&Verschoore, 2008).

A estruturação em rede pode garantir benefícios ligados à concorrência e ao desenvolvimento da própria organização. Nesse sentido, o conhecimento acerca de Governança Democrática em Rede vem explicar como a rede de cooperação irá funcionar para atender às demandas da sociedade em um determinando ambiente demográfico no qual se espera que esta formação possa operar redes em conformidade com ideias democráticas (Denhardt, 2012).

\subsection{O contexto das ONGs e da governança democrática.}

Um evento que se destaca na realidade organizacional é o crescimento das chamadas empresas socialmente responsáveis. Várias são as definições e posicionamentos a respeito da concepção destas empresas e do papel desempenhado por elas por meio de projetos sociais, doações financeiras ou até mesmo minimização de impactos causados ao ambiente em que se 
encontram. Contudo, em meio às ações sociais realizadas pelas empresas contemporâneas é possível que sejam encontrados resquícios de objetivos estritamente empresariais atrelados aos objetivos da própria instituição que podem não buscar a solução da raiz de conflitos realmente sociais.

Por outro lado, o Terceiro Setor (Sindicatos, Associações e Organizações Não governamentais - ONGs) acumula responsabilidades no que tange à melhoria e equilíbrio das condições social. Dentro deste panorama, as ONGs têm um caráter particular, por atuar de maneira especificamente social sem que assumam, ao menos em tese, posições políticas ou beneficiem uma parcela da sociedade em detrimento de outras.

De acordo com Montenegro (1994), ONGs são:

Um tipo particular de organização que não dependem nem economicamente nem institucionalmente do Estado, que se dedicam a tarefas de promoção social, educação comunicação e investigação/experimentação, sem fins de lucros e cujo objetivo final é a melhoria da qualidade de vida dos setores mais oprimidos (Montenegro, 1994, p.11).

A utilização do termo ONG para nomear agentes, parcialmente destituídos de interesses econômicos e voltados à promoção de mudanças socioeconômicas foi cunhada a partir do ano de 1948 quando as Nações Unidas criaram o Sistema Internacional de Cooperação ao Desenvolvimento, dando destaque às ações no Terceiro Mundo (Buarque \& Vainsencher, 2001). No Brasil, essas organizações surgem como forma de preencher carências de assistência social em diversos aspectos como educação, saúde, esportes, lazer, inclusive apoiando movimentos sociais e associações.

No que concerne à ideia de Governança Democrática diz respeito a um processo no qual é estabelecido interação entre entes governamentais, o mercado e a sociedade civil, que de forma conjunta promovem a coordenação e cooperação de ações públicas, além de garantir e estender a participação para os diferentes segmentos sociais envolvidos nas decisões de políticas públicas (Santos, Ribeiro \& AZEVEDO, 2004). Para Carrion e Costa (2010, p.626) o termo é relativo a um sistema "contínuo de cooperação e de acomodamento entre interesses diversos e conflituais, que inclui as instituições oficiais (...) assim como os arranjos informais em torno dos quais chegou-se ao acordo".

O processo de governança democrática surgiu a partir de uma crise do Estado como ator responsável pela promoção do bem-estar social demandando do mesmo um novo posicionamento no cenário econômico e globalizado. A postura dos cidadãos na buscar por uma maximização de seus interesses no curto prazo, negligenciando políticas e propostas de longo prazo, serviu também para agravar a crise econômica e social na qual o Estado se viu sobrecarregado (BEVIR, 2011).

Nesse sentido, entende-se que a governança não pode ser considerada apenas numa dimensão relacionada ao governo, uma vez que irá envolver uma maneira mais holística de enxergar um cenário global. É o que defende Esteve (2009):

"A governança, portanto, vai implicar, de uma forma concreta, a reestruturação global da maneira de governar de um governo local. É por isso que dizemos que a governança é o modo de governar próprio do governo-rede ou relacional, que 
é o adequado à nova sociedade em rede, também denominada sociedade do conhecimento" (Esteve, 2009, p.37).

Gohn (2004) tece algumas reflexões acerca da questão da cooperação que envolve uma estrutura de governança. O autor acredita ser um conceito bastante discutível e de suma importância ao se tratar do desenvolvimento de atividades em conjunto com atores autônomos envolvidos. Ainda segundo o autor, existe uma necessidade de construir relações de consenso coletivo e ações cooperadas para que se cumpra o "compromisso da articulação no âmbito institucional, tão necessária para a administração de conflitos e para a integração de ações de apoio ao desenvolvimento" (Gohn, 2004, p.1855).

Tratando do estabelecimento de relações de parceria no desenvolvimento de projetos, ou ainda auxílio no crescimento e maturação de uma entidade, é possível perceber a complexidade das relações instauradas entre atores que possuem objetivos os mais diversos, contudo, são capazes de assumirem consciência grupal para solucionar ou melhorar questões inerentes a coletividade.

Investigar as redes em contextos de ONGs e a partir da perspectiva de governança democrática é importante para que se possa refletir acerca de alternativas adequadas e suficientemente flexíveis, porém responsáveis, para que sejam estabelecidas relações estruturadas entre os diferentes atores sociais, orientadas para a eficiência e eficácia dos seus processos, porém também pautadas em relações de confiança, de cooperação e de participação voluntária.

\section{METODOLOGIA}

A análise de redes sociais envolve a observação gráfica de relações entre indivíduos diversos. Apesar da independência das entidades, observa-se uma preocupação com o alcance de um objetivo em comum, um objetivo social e democrático. Há ainda um alto grau de complexidade nas relações não hierárquicas e autônomas na construção de um relacionamento sólido em uma estrutura de governança, a qual deve ser considerada uma vez que a análise desta disposição empírica, abstrata e limitada acompanhou o processo de trabalho deste estudo.

Contudo, para construção de uma análise que auxiliasse no entendimento destas relações, foram utilizadas, dentro das possibilidades metodológicas oferecidas pelo software PAJEK, medidas que auxiliassem uma análise técnica própria para o estudo, sendo elas: densidade, centralidade e núcleos.

Para melhor entendimento dos resultados obtidos, faz-se necessário o entendimento do termo "núcleo" que no programa nos é apresentado como "k-core". Os núcleos são relações fortemente instauradas dentro de uma rede. Uma mesma rede pode ter mais de um aglomerado de instituições intimamente relacionadas e, neste caso, a rede possui mais de um núcleo. $O$ software apresenta como definição em seu manual, núcleo-k como um subconjunto de vértices onde cada vértice do subconjunto é ligado pelo mesmo número " $\mathrm{k}$ " de vértices.

Um grande número de núcleos e a maneira com que estes se dispõem no desenho da rede, podem auxiliar na definição do grau de densidade da estrutura. Conforme supracitado neste trabalho, uma rede densa de contato, pode ser uma grande ferramenta para construção de relações significativas que podem alavancar resultados pessoais e de todos os elos envolvidos. 
Neste trabalho, foram observados diversos núcleos, porém considerados relevantes para densidade de uma estrutura, apenas subgrupos envolvendo no mínimo três ligações.

Objetivando compreender a importância de um comportamento em conjunto, e a dependência dos atores com relação à estrutura inserida, fez-se necessário analisar o conjunto de relações instauradas por completo, não evidenciando características individuais das instituições.

\subsection{Classificação da Pesquisa, Local de estudo, unidade de análise}

A escolha do cenário a ser estudado se deve ao elevado número de instituições não governamentais atuantes na cidade de Viçosa - localizada na Zona da Mata do estado de Minas Gerais - sendo 16 ONGs cadastradas no catálogo formulado pela Associação de Desenvolvimento de Viçosa (ADEVI), em 2013 durante a execução do Encontro de Tecnologias Sociais Aplicadas a Viçosa e Região, o qual será utilizado como dado secundário para este estudo.

O evento foi uma iniciativa da ADEVI e demais indivíduos que, com auxílio da Fundação de Amparo à Pesquisa do Estado de Minas Gerais (FAPEMIG) e da Universidade Federal de Viçosa (UFV), realizaram um trabalho exaustivo para agrupar informações a respeito das ONGs existentes na localidade e suas relações de parcerias estabelecidas.

Apesar do número inicial reduzido de organizações participantes no evento, a relação de parceiros descrita foi extensa e possibilitou a formulação do desenho da governança estabelecida na cidade, no que diz respeito às ONGs.

\subsection{Procedimentos de coleta e análise de dados}

Foi utilizado, o software de análise de redes PAJEK XXL, por meio do qual foram calculadas medidas de posicionamento visando fornecer a estruturação das ONGs em formato de um mapa. Em termos de organização, os dados foram previamente organizados por meio de um código baseado na atividade da instituição correspondente visando preservar o anonimato da organização. Na ferramenta base utilizada para obtenção de dados secundários (o catálogo), foram mencionadas 38 organizações entre ONGs, associações, secretarias municipais e empresas juniores da UFV. Ao esmiuçar os parceiros institucionais envolvidos na produção de eventos, na obtenção de recursos e em demais atividades organizacionais, chegou-se a um número de 123 instituições, as quais foram organizadas em categorias.

A partir de então foram verificados elos, instituições que possuem conexões e troca de informações entre si, que de acordo com o catálogo utilizado, possuíam relações de parceria entre as entidades previamente citadas, totalizando 276 conexões. Ademais, com o detalhamento das organizações parceiras, foram estabelecidas novas categorias, sendo elas: órgãos públicos ou mistos, entidades do terceiro setor e instituições privadas.

Para analisar cada ator individualmente, foram utilizadas diferentes mensurações de centralidade e interatividade, as quais o próprio programa oferece como forma de análise. Foram estas: centralidade e periferia, proximidade, ligações curtas e longas e número de cruzamentos.

Assim sendo, as organizações com maior cruzamento de dados, ou seja, maior interrelação com as demais, serão consideradas organizações centrais formando então, uma rede densa ao seu redor garantindo uma possível distribuição de riscos e maior acesso às informações. 
Ademais, foi observado o comportamento de todas as entidades envolvidas na rede social formada e destacadas as sobressalentes a partir da análise.

\section{DESCRIÇÃO E ANÁLISE DOS DADOS}

A seguir serão apresentados os resultados do cruzamento de dados no software PAJEK e a análise dos mesmos. Dentre as possibilidades oferecidas pela ferramenta, foram abordados os tópicos que propiciariam uma melhor compreensão quanto ao objetivo deste trabalho. Foram estes: Densidade, Núcleos e Centralidade.

\subsection{Densidade da rede}

A primeira medida mensurada foi a quantidade de ligações existentes entre os atores inseridos no programa entendida como densidade da rede. Através dessa medida é possível averiguar a concentração de conexões estabelecidas entre os atores e classificar as redes como densas ou difusas. Uma rede densa, além de possuir muitos elos, dispõe de uma dispersão do grau de conexões, ou seja, garante uma homogeneidade de ligações.

O desenho geral da rede pode ser observado na Figura 1, que apresenta o resultado de todas as relações traçadas entre as organizações pertencentes ao catálogo e as instituições privadas ou públicas que fazem parte desta grande rede de contatos. Conforme supracitado foram processados 276 elos entre as 123 organizações cadastradas ou citadas no catálogo utilizado como suporte à realização deste estudo. O programa apresentou um número total de 18 componentes considerados fortes, sendo estes, responsáveis por ligações formadas a 80,48\% da rede geral, totalizando 99 vértices conectados.

Em uma rede formada por 123 atores, obter um resultado em que mais de $80 \%$ das instituições estão ligadas a apenas $14,63 \%$ das entidades (18 componentes) demonstra uma concentração de informação e uma possível falha na distribuição dos benefícios alcançados em uma estrutura de rede. Ademais, é eminente a existência de uma relação de poder estabelecida, onde a concentração do mesmo se dá nos componentes fortes. Estes recebem mais informações e são considerados importantes elos para a rede geral, isto porque são decisivos para a condução e manutenção do fluxo de comunicação.

Inicialmente é possível localizar regiões de maior densidade de comunicação, obtendo mais de um ponto com grande fluxo de informação. Apesar da estrutura da rede funcionar de forma dinâmica e instável, o que garante que atores sejam atingidos indiretamente, é possível, por meio de uma análise empírica, compreender que entidades que centralizam os subgrupos, ocupam uma posição favorável à construção dos objetivos e a instauração de relações de poder.

Previamente, é possível observar ainda a prevalência de atores periféricos que possuem relações sem contato, ou seja, configuram uma ausência de associação demonstrando pouco ou nenhum vínculo. Sobre a Figura 1 apresentada a seguir, tem-se a apresentação dos seguintes códigos: ONG - Organização não Governamental, CON - Conselhos, SEC - Secretarias, EJR Empresas Juniores, PEM - Órgãos Púbicos ou mistos, TER - Entidade do Terceiro Setor e PRI Organizações Privadas. 
Figura 1: Desenho da rede geral de relação estabelecidas entre ONGs e demais entidades de Viçosa-MG.

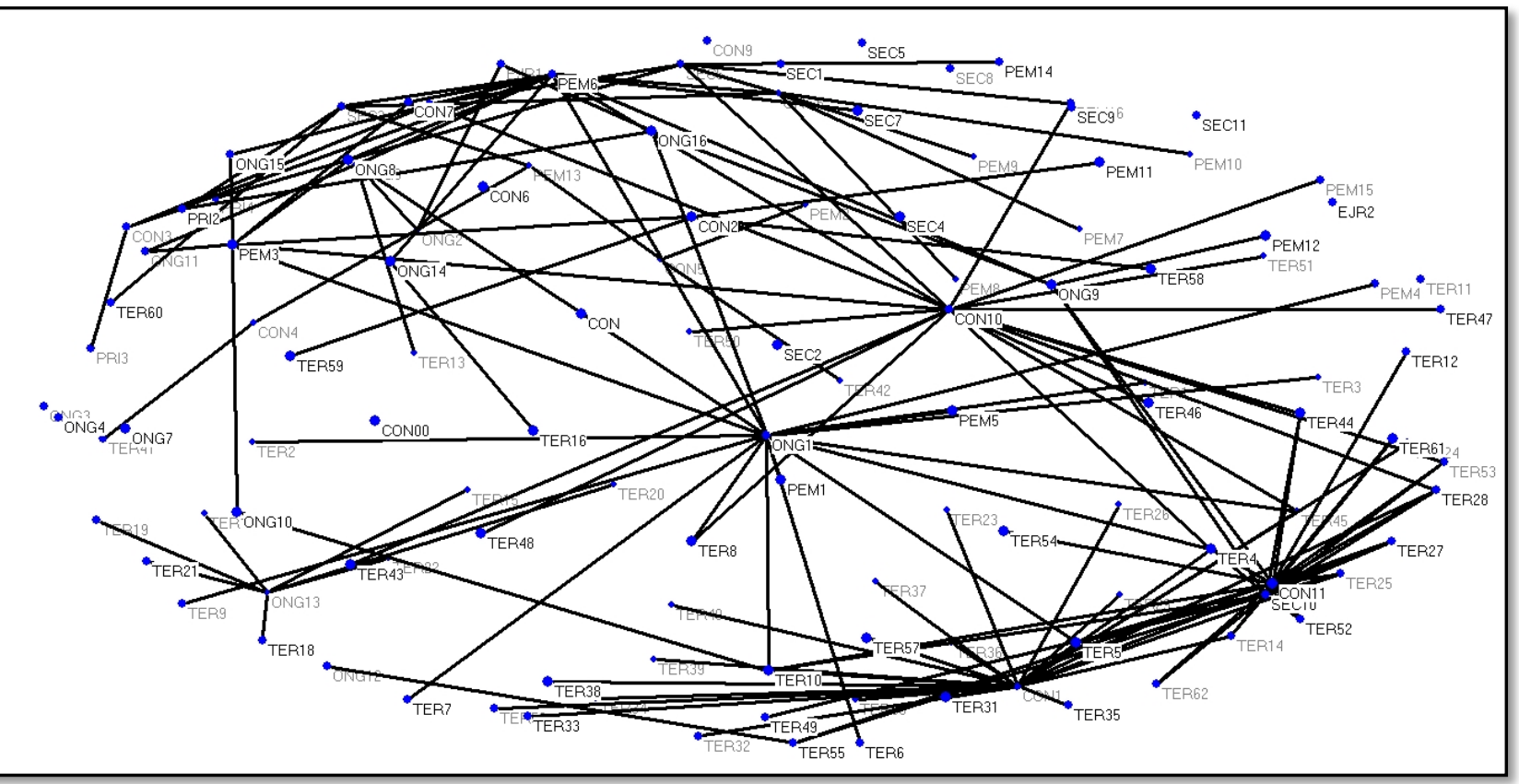

Fonte: Dados da Pesquisa, 2014.

\subsection{Núcleo}

Núcleos são conjuntos de instituições que formam subgrupos dentro de uma rede. Os resultados deste trabalho apresentaram quatro subgrupos, nos quais os atores envolvidos possuem um número mínimo de ligações entre si, e ainda formam uma rede fechada dentro da estrutura geral. Como forma de obter maiores detalhes da rede formada por instituições consideradas fortes dentro da estrutura geral, escolheu-se a opção de um núcleo-3, o que significa que os atores envolvidos estão ligados à no mínimo três vetores e se conectam.

A Figura 2 mostra o desenho gráfico deste núcleo, e facilita a compreensão dos pontos de massa onde as relações podem ser consideradas possivelmente mais ativas e compactas. Ao estabelecer uma análise em conjunto com a Figura 1 previamente apresentada, é possível assimilar que, instituições pertencentes a uma junção de elos cuja densidade é maior, acabam por se conectarem entre si formando uma rede de fortes entidades. 


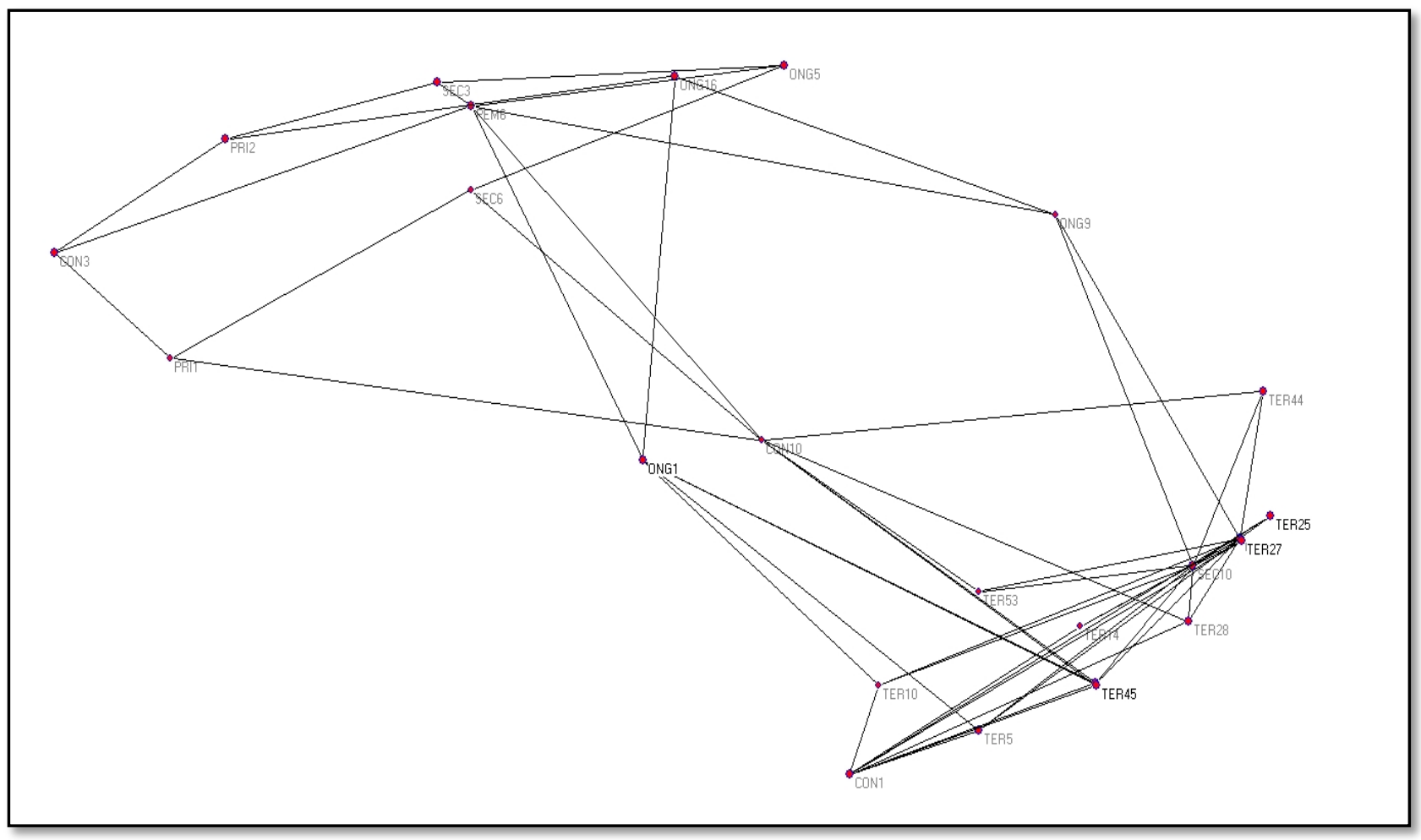

Figura 2: Atores pertencentes a núcleos fortes

Fonte: Dados da pesquisa, 2014.

Como uma rede social os indivíduos não obtém informação apenas em suas relações diretas, mas também por meio de otimização de contatos em relações com outros núcleos, entidades, ampliando sua participação e interagindo com a rede geral. Tal ação não significa, contudo, deixar de pertencer ao seu aglomerado, mas aumentar as possibilidades de acesso à informação.

\subsection{Centralidade}

De maneira geral, a centralidade de uma rede demonstra o grau ou quantidade de fluxos de comunicação que envolve um determinado ator. Um elo com uma grande quantidade de vínculos indica uma entidade em uma boa posição com relação ao fluxo de informações e contato com os demais atores. Isto porque, demonstra acessibilidade e intimidade que pode favorecer a instituição central numa relação de poder, uma vez que são responsáveis por colocar demais organizações em proximidade.

Objetivando destacar quais instituições exercem papel de maior influência sobre a rede, faz-se necessário uma análise da centralidade da estrutura. E se por um lado o índice de centralidade revela sua importância, a análise das posições periféricas também é de grande valia. Isto porque, ao observar aglomerações centrais em uma rede, por consequência há de se encontrar atores evidenciados por estarem posicionados em locais periféricos. Tais atores são inertes à estrutura de rede e fazem parte de elos pouco estimulados e sem fortes relações de troca de informação. 
Ao se analisar a posição de um ator com relação à centralidade é fundamental propor uma estrutura de análise. Desta forma, optou-se por demonstrar os resultados em um quadro no qual pode ser observado um ranking simples mas que permite a comparação entre a colocação das instituições. No Quadro 1 a seguir, destacam-se as instituições com números de interações superiores perante a rede.

Quadro 1: Ranking de atores centralizados

\begin{tabular}{|c|l|c|}
\hline INDIVIDUO & CAMPO & № DE LIGAÇÕES \\
\hline 18 & Órgão público & 25 \\
\hline 27 & Órgão público & 18 \\
\hline 1 & Terceiro setor & 18 \\
\hline 38 & Órgão público & 15 \\
\hline 28 & Órgão público & 14 \\
\hline
\end{tabular}

Fonte: Dados da pesquisa, 2014.

A rede analisada possui uma grande concentração de elos ligados a um pequeno número de atores, conforme foi confirmado ao analisarmos a densidade. O que é evidenciado aqui são as instituições que se tornam centrais e influentes nas conexões de toda a conjuntura. Um ator responsável por 25 elos, por exemplo, torna-se encarregado de atuar como conector de diversas entidades.

No caso da rede em análise, é interessante atentar à natureza dos atores destacados. Em sua maioria, sobressaíram órgãos públicos, o que demonstra a importância da atuação do poder público para a manutenção desta rede. Apesar de estarmos teoricamente nos readaptando a um novo espaço público, ainda não contamos com o controle de situações públicas enquanto sociedade civil, a não ser que tenhamos o auxílio ou mesmo a presença do governo.

Ademais, a estrutura encontrada apresenta diversas instituições periféricas ligadas apenas a um elo. Desta forma, considerando os demais dados obtidos, compreende-se que a concentração das conexões em um número relativamente pequeno de órgãos centrais, origina um número maior de atores periféricos.

A partir da listagem obtida, percebe-se que a atual situação de governança constituída na cidade de Viçosa - MG não tem favorecido a atuação de ONGs e instituições do terceiro setor. Apesar do crescente número de instituições de cunho sociais, há certa dependência no que diz respeito à formação de parcerias com órgãos governamentais. Isto porque, dentre as cinco organizações centrais indicadas pelo programa, quatro são instituições públicas e apenas uma é uma ONG.

\section{CONSIDERAÇÕES FINAIS: REDE E INFORMAÇÃO}

O estudo realizado mostrou que a rede estudada pode ser classificada como sendo pouco densa no que diz respeito à quantidade de elos, difusa, pois evidenciou uma alta concentração de conexões em atores centrais gerando inúmeros atores periféricos pouco relacionados e com alto potencial de crescimento devido à presença de um núcleo forte e bem estruturado. Foi visto que o emprego da metodologia de análise de redes permitiu obter um panorama das conexões e construções sociais do objeto de estudo: ONGs e a estrutura de governança democrática em rede a qual estão inseridas. 
Ao se analisar uma rede social, a existência de um alto índice de centralidade torna atores referência em movimentos e projetos que envolvam a sociedade, podendo ser considerados meios de liderança capazes de mobilizar a rede. Os maiores destaques desta rede em questão são figuras públicas, o que reforça a importância de uma atuação de forma mais participativa do poder público.

No caso da cidade de Viçosa, advertindo que o enfoque inicial foi no comportamento das ONGs em meio a estrutura, na análise destes dados destacou-se a Associação de Desenvolvimento de Viçosa (ADEVI) como potencial mediador, capaz de estabelecer laços estáveis. Essa instituição, pertencente ao terceiro setor apresenta alto índice de elos (18 no total), além de ser apontada pelo programa como sendo pertencente a um núcleo forte (núcleo k-3). Seu destaque deve-se provavelmente a natureza do trabalho exercido visto que se trata de uma associação que busca o desenvolvimento econômico e social da região por meio da articulação de interesses entre demais instituições.

Foi destacada a falta de coordenação e a dispersão existente entre as ONGs da cidade. Um ambiente pouco denso e com um alto número de atores periféricos não favorece a atuação destas organizações, principalmente ao notar que tais entidades (em sua maioria) não ocupam espaços de destaque. Vale ressaltar ainda, que a presença de um núcleo forte, demonstra o potencial de maior interação geral, uma vez que este subgrupo pode fomentar a formação de demais, e fortalecer a rede por completo.

Ressaltam-se as limitações encontradas para a realização desta pesquisa, no que diz respeito à utilização de dados secundários. Tais dados foram fornecidos por uma ONG atuante na cidade que se propôs a executar um trabalho minucioso de coleta de informações que culminou com a elaboração do catálogo de informações já mencionado.

Em relação à estrutura, poucas são as organizações que se destacam na conjuntura. A maioria dessas pertencem ao âmbito público, porém com a característica de dificuldades na implementação de um espaço público de efetiva participação social. A sociedade civil e mesmos as ONGs ainda mantem seus alicerces ligados à atores públicos mantendo uma certa dependência de tais figuras para atuação na cidade. Tal afirmativa foi observada no ranking de atores centralizados que demonstrou que muitas das instituições apenas estabelecem contato com outras por meio de iniciativas públicas como Universidades e órgãos da administração pública direta.

Como decorrência, o estudo indica aos gestores de ONGs que muito do potencial destas entidades pode estar sendo pouco explorado. Faz-se necessário uma maior verificação da eficácia de atuação de tais organizações, porém, o baixo nível de troca de informações revela um impedimento à distribuição de riscos e um processo de aprendizagem coletiva, onde os erros cometidos tornam-se experiências e os casos de sucesso podem ser incorporados às práticas organizacionais. Cabe às organizações se posicionarem de forma mais efetiva perante seus parceiros de atuação para que consigam atingir com maior eficiência seu público alvo, facilitar a execução de processos e o regime de aprendizagem.

Aos formuladores de políticas públicas, atenta-se para o potencial articulador que dispõem sobre a formulação de políticas e ações públicas. Apesar de um grande número de ONGs, o poder público continua sendo central e ator de suma importância para a manutenção da rede e das conexões. Em seus variados níveis de atuação, a atuação do poder público no estudo 
se mostrou parte de elos e núcleos que sustentam toda a estrutura da rede, o que sugere que sua inexistência ou má atuação implica em potencial perda para o conjunto.

Notou-se ainda um alto potencial de formação de conexões fortes. A rede foi considerada pelo software como sendo densa e possui um núcleo forte o que reflete um potencial de proximidade alto. $\mathrm{O}$ cenário se mostra então desigual, o que exige uma reflexão acerca das falhas de cada instituição não pertencente a uma posição de destaque.

A interpretação dos dados obtidos nesta pesquisa elucida alguns ângulos que apontam organizações centrais, densidades e também lacunas na estrutura por completo. Torna-se necessária a construção de conhecimento coletivo e a identificação de novas abordagens que possam incrementar os posicionamento e reflexões aqui obtidos, bem como uma adaptação à atualização do catálogo do estudo e aplicação em demais cidades, possibilitando uma análise comparativa.

\section{REFERENCIAS}

BALESTRIN, A.; VERSCHOORE, J.; REYES, E. (2008). Redes de cooperação empresarial: estratégias de gestão na nova economia. Bookman.

BEVIR M. (2011). Governança democrática: uma genealogia. Revista de Sociologia e Política. 19 (39), 103-114.

BUARQUE. C, VAINSENCHER. S. A. (2001). ONGs no brasil e a questão de gênero. Trabalhos para discussão, № 123, Novembro. Disponível em < https://periodicos.fundaj.gov.br/TPD/article/download/932/653 >. Acessado em junho de 2016.

CARRION R.M COSTA P. A. (2010). Governança Democrática, Participação e Solidariedade: Entre a Retórica e a Práxis. Espacio Abierto Cuaderno Venezolano de Sociología. 19 (4), 621 - 640.

DENHARDT. R.B. (2012). Teoria Geral da Administração Pública. Editora Cengage Learning. (6 ${ }^{a}$ ed.). Rio de Janeiro.

ESTEVE J. M. P. (2009). Governança democrática: construção coletiva do desenvolvimento das cidades. Belo Horizonte.

FONTES, B. A. S. M. (2004). Capital Social e terceiro setor: sobre a estruturação das redes sociais em associações voluntárias. Recife: Editora Universitária UFPE.

GOHN M. G. (2004). Empoderamento e participação da comunidade em políticas sociais. Saúde e Sociedade, 13 (2), 20-31.

MARTELETO. R. M. (2001). Análise de redes sociais- aplicação nos estudos de transferência de informação. Instituto Brasileiro de Informação em Ciência e Tecnologia (Ibict), 30 (1), 71-81.

MIZRUCHI. M. S. (1994). Social network analysis: recent achievements and current controversies. Fórum: Análise de redes sociais: avanços recentes e controvérsias atuais. 37 (4), 329-343.

MONTENEGRO, T. (1994). O que é ONG. São Paulo, SP: Brasiliense.

PARDINI J. D, TEIXEIRA A. R. F, AZEVEDO A, OLIVEIRA S. G. (2012). A influência do sistema de redes de relações sociais no exercício de empreender em serviços odontológicos. III Colóquio de Redes Estratégia e Inovação. Lavras.

RIBEIRO, E. M. B. e BASTOS, A. V. B. (2011). Redes sociais interorganizacionais na efetivação de 
projetos sociais. Psicologia \& Sociedade; 23 (2), 282-292.

SANTOS, O. A., Jr.; RIBEIRO, L. C. Q.; AZEVEDO, S. (Orgs). (2004). Governança democrática e poder local: a experiência dos conselhos municipais no Brasil. Rio de Janeiro: Revan, Fase.

SILVA E.E, LASMAR F.C, PEREIRA J. R. (2012) Redes sociais: o caso da parceira de uma instituição federal de ensino superior de Minas Gerais. III Colóquio de Redes Estratégia e Inovação. Lavras.

SOUZA L. B, FREITAS M. F, SILVA D. F. (2012). Um estudo sobre as redes intra-organizacionais existentes nos assentamentos rurais Lago Azul e Lagoa dos Mares. III Colóquio de Redes, Estratégia e Inovação. Lavras.

Quadro da relação das diferentes organizações presentes no catálogo e trabalhados no software PAJEK, descritas por meio de códigos para fins de preservação da identificação das mesmas.

\begin{tabular}{|l|l|}
\hline \multicolumn{2}{|l|}{ RELAÇÃO DAS ORGANIZAÇÕES INDICADAS NO ESTUDO } \\
\hline ONG 's & Parceria \\
\hline ONG1 & - \\
\hline & $\begin{array}{l}\text { TER1; PEM1; PEM6; PEM4; PEM5; PEM3; TER2; } \\
\text { *ONG2 }\end{array}$ \\
\hline ONG3 & TER9; TER10; TER11; TER45 \\
\hline ONG4 & - \\
\hline ONG5 & - \\
\hline ONG6 & PEM7; PEM8; PEM9; PEM10; PEM6; SEC3; SEC6 \\
\hline ONG7 & ONG2; TER13; PEM6 \\
\hline ONG8 & - \\
\hline ONG9 & PEM3; PEM6 \\
\hline ONG10 & PEM12; PEM6; ONG16 \\
\hline ONG11 & TER10; PEM3 \\
\hline ONG12 & PEM3; TER28 \\
\hline ONG13 & TER55 \\
\hline ONG14 & TER15, TER17, TER18, TER19, TER20, TER21, \\
\hline ONG15 & TER22 \\
\hline ONG16 & TER16; PEM6 \\
\hline ONG17 & PEM3; PEM6 \\
\hline Conselhos & ONG9; PRI2 \\
\hline CON1 & - \\
\hline CON2 & Parcerias \\
\hline & $\begin{array}{l}\text { TER23, TER24, TER25, TER26, TER27, TER28, TER4, } \\
\text { TER14, TER5, TER29, TER45, TER30, TER31, TER32, } \\
\text { TER33, TER34, TER335, TER36, TER37, TER38, } \\
\text { TER39, TER40, TER10, TER56, TER57 }\end{array}$ \\
\hline & EMATER, PEM3, PEM11, TER58, TER59. \\
\hline
\end{tabular}




\begin{tabular}{|c|c|}
\hline CON4 & TER41, PEM13 \\
\hline CON5 & TER42, PEM2, PEM6. \\
\hline CON6 & - \\
\hline CON7 & PEM3, PEM6 \\
\hline CON8 & - \\
\hline CON9 & - \\
\hline CON10 & $\begin{array}{l}\text { TER43, TER44, TER45, TER28, TER47, TER48, } \\
\text { TER46, TER50, TER51, PEM6, PEM15, PEM3, } \\
\text { PEM15, PEM16, TER4, TER8, TER53, PRI1, SEC6, } \\
\text { SINTESS, PEM6. }\end{array}$ \\
\hline CON11 & $\begin{array}{l}\text { TER25, TER27, TER28, TER4, TER14, TER61, TER5, } \\
\text { TER44, TER52, TER54, TER62, ONG9, TER53, } \\
\text { TER54, TER10, TER55, TER61. }\end{array}$ \\
\hline Secretárias & Parceiras \\
\hline SEC1 & - \\
\hline SEC2 & - \\
\hline SEC3 & PEM6, PRI2, SEPIAG, TER60, PEM13 \\
\hline SEC4 & - \\
\hline SEC5 & - \\
\hline SEC6 & PEM14, PEM16 PRI1, PRI4 \\
\hline SEC7 & PEM6 \\
\hline SEC8 & - \\
\hline SEC9 & - \\
\hline SEC10 & $\begin{array}{l}\text { TER25, TER27, TER28, TER12, TER4, TER14, } \\
\text { APONE, TER5, AVIRC, TER52, TER62, TER49, } \\
\text { ONG9, TER53, TER10, TER55. }\end{array}$ \\
\hline SEC11 & - \\
\hline Empresas Jr. & Parceiras \\
\hline EJR1 & ONG16, ONG2; \\
\hline EJR2 & - \\
\hline Órgãos Público ou misto & Indicados no catálogo (16) \\
\hline Cód. & PEM1 a PEM16 \\
\hline ENTIDADES DO 30 SETOR & Indicadas no catálogo (62) \\
\hline Cód. & TER1 a TER62 \\
\hline Organizações Provadas & Indicadas (4) \\
\hline Cód. & PRI1 a PRI4 \\
\hline
\end{tabular}

